\title{
Road Vehicle-Bridge Interaction considering Varied Vehicle Speed Based on Convenient Combination of Simulink and ANSYS
}

\author{
Helu Yu, ${ }^{1}$ Bin Wang $\mathbb{D}^{1},{ }^{1}$ Yongle Li $\mathbb{D},{ }^{1}$ Yankun Zhang, ${ }^{1}$ and Wei Zhang ${ }^{2}$ \\ ${ }^{1}$ Department of Bridge Engineering, Southwest Jiaotong University, Chengdu 610031, China \\ ${ }^{2}$ Department of Civil and Environmental Engineering, University of Connecticut, Storrs, CT 06269, USA \\ Correspondence should be addressed to Bin Wang; wangbinwvb@home.swjtu.edu.cn
}

Received 8 March 2018; Revised 12 June 2018; Accepted 26 June 2018; Published 15 July 2018

Academic Editor: Itzhak Green

Copyright (C) 2018 Helu Yu et al. This is an open access article distributed under the Creative Commons Attribution License, which permits unrestricted use, distribution, and reproduction in any medium, provided the original work is properly cited.

\begin{abstract}
In order to cover the complexity of coding and extend the generality on the road vehicle-bridge iteration, a process to solve vehiclebridge interaction considering varied vehicle speed based on a convenient combination of Matlab Simulink and ANSYS is presented. In this way, the road vehicle is modeled in state space and the corresponding motion equations are solved using Simulink. The finite element model for the bridge is established and solved using ANSYS. The so-called inter-history iteration method is adopted to realize the interaction between the vehicle model and the bridge model. Different from typical method of road vehicle-bridge interaction in the vertical direction, a detailed longitudinal force model is set up to take into account the effects of varied vehicle speed. In the force model, acceleration and braking of the road vehicle are treated differently according to their mechanical nature. In the case studies based on a simply supported beam, the dynamic performance of the road vehicle and the bridge under varied vehicle speeds is calculated and discussed. The vertical acceleration characteristics of the midpoint of beam under varied vehicle speed can be grouped into two periods. The first one is affected by the load transform between the wheels, and the other one depends on the speed amplitude. Sudden change of the vertical acceleration of the beam and the longitudinal reaction force are observed as the wheels move on or off the bridge, and the bridge performs different dynamic responses during acceleration and braking.
\end{abstract}

\section{Introduction}

Because of the excitation from vehicles' wheels, a bridge will produce dynamic deformation and vibration when a vehicle passes on, and the dynamic responses of the bridge will affect the dynamic performance of the vehicles in turn, that is, the so-called vehicle-bridge interaction (VBI) problem. Early researches on VBI were mainly focused on railway bridges. The reason is that the coupling effects between the train and the bridge are obvious due to the relative heavy axles of the train. However, with the increase of the bridge span and the axle weigh of road vehicles on highway, VBI problem for road vehicles on highway bridges is becoming more and more prominent.

In VBI, the motion equations of vehicles and bridges need to be established firstly, and they are coupled together by the interaction forces at the contact positions between the vehicles and the bridge decks. In order to solve the VBI systems, several analytical methods have been proposed. These basic methods are applicable for both highway traffic and railway traffic in general. Blejwas et al. [1] solved the VBI system by adopting the Lagrange multipliers to couple the motion equations of the vehicles and the bridges. However, this method leads to an increase of the computational cost. Yang and Lin [2] used the dynamic condensation method to condense the degrees of freedom (DOFs) of the vehicle to the associated bridge, then the integral equation of the VBI system can be derived and solved. This method is efficient for computing the bridge responses, but it is not adequate for computing the vehicle responses. Li et al. [3] and Zhang and Xia [4] divided the VBI system into two subsystems; the motion equations of the vehicle and the bridge are established and solved, respectively, with an iterative procedure. The difference is that $\mathrm{Li}$ et al. [3] used the time-step iteration, 
while Zhang and Xia [4] used the intersystem iteration to solve the VBI system. It should be pointed out that the achievement of the above numerical methods for solving the VBI problem generally requires a compilation of complex computer programs, and the generality of these programs is also limited to a certain extent.

In most researches on VBI, the vehicles are assumed to move with constant speeds. Limited attention has been paid to the effects of the longitudinal forces between the vehicles and the bridge on the dynamic responses. Actually, the change of the longitudinal forces caused by the change of the vehicle speed may affect the dynamic responses of the system. Yang and $\mathrm{Wu}[5]$ investigated the behavior of a bridge subjected to a train in deceleration by using a versatile element to treat the interaction between the vehicle and the bridge. In their study, the longitudinal contact forces between the wheels and the bridge were simply considered as the product of the vertical contact forces and a friction coefficient. Law and Zhu [6] also performed numerical studies on the dynamic responses of bridges considering the effects of braking. A total braking force was adopted and several levels of the braking force were assumed in the study. Azimi et al. [7] proposed a modified two-dimensional VBI element, in which the effects of the vehicle acceleration are considered as external loads acting on each part of the vehicle masses. The responses of a bridge subjected to the vehicle experiencing sudden deceleration were studied. Deng et al. [8] proposed a three-dimensional vehicle-bridge coupled model to study the dynamic impact factors for bridges due to braking. An inertial force calculated from the vehicle mass and the horizontal acceleration was forced on the vehicle to consider the braking effects. In the above studies, the interaction forces due to the change of vehicle speeds are simplified greatly as not to express the detailed interaction force status in the longitudinal direction, particularly for the road vehicle.

In order to cover the complexity of VBI coding and extend the generality, a method to solve VBI for road vehicle based on the numerical simulation software Matlab Simulink and the finite element software ANSYS is presented in this paper. ANSYS and Simulink are used to solve the motion equations of the bridge and the road vehicle, respectively. In this method, the iterative solution procedure is achieved by compiling a main program to link and communicate the data in the two software packages. Therefore, not only can the compilation of complex computer programs for solving the VBI be avoided, but also various complex models of bridges and vehicles can be easily established. In order to verify the reliability of the combination of the software, a typical example adopted by many researchers that a simply supported beam subjected to a moving suspended rigid beam is studied, and the results are in good agreement with these given in Yang and $\mathrm{Wu}$ [5]. In order to analyze the dynamic responses of the bridge and the vehicle with varied vehicle speed, a vehicle model is established with detailed longitudinal force models. Through the analysis of a simply supported beam subjected to a vehicle with varied speeds, the effects of the vehicle speed, acceleration, road roughness, and bridge damping on the dynamic response of vehicle and bridge are studied.

\section{Vehicle-Bridge Interaction considering Varied Vehicle Speed}

As discussed in Section 1, typical VBI systems were mainly focused on the dynamic performance in the vertical direction. In this section, a VBI system for highway considering both the vertical and the longitudinal interaction forces will be presented, after introducing the detailed longitudinal tire forces between the vehicle and the bridge under acceleration and braking. The VBI system is divided into the vehicle subsystem in state space and the bridge subsystem using the finite element method. In this way, the vehicle subsystem can be easily modeled and solved in Simulink while the bridge subsystem can be modeled and solved directly using Ansys.

2.1. Vehicle Subsystem in State Space. A real vehicle is a multibody dynamic system with high complexity. In VBI, the real vehicle should be simplified to a numerical model with a few DOFs, which will reduce the complexity of the research issues without affecting the accuracy of the results. Several simplified vehicle models have already been proposed as in Obrien et al. [9], Zhang and Cai [10], Li et al. [11], Antolin et al. [12], and Ettefagh [13]. A 7-DOF vehicle model with a vehicle body and 4 wheels is used in this study, which is similar to the model in Crolla and Yu [14]. As shown in Figure 1, the vehicle body and the wheels are assumed to be rigid bodies, and the suspension system is modeled as a linear elastic system represented by springs and dampers. The vehicle body has 3 DOFs: the displacement in the vertical direction ( $z$-axis) and the rotation displacements about the $x$-axis and $y$-axis. Each wheel has a DOF: the displacement in the vertical direction (z-axis).

Based on the D'Alambert principle, the motion equations of the vehicle model can be expressed as

$$
\begin{aligned}
& m_{b} \ddot{Z}_{b}-C_{s}\left(\dot{Z}_{w 1}-\dot{Z}_{b 1}+\dot{Z}_{w 2}-\dot{Z}_{b 2}+\dot{Z}_{w 3}-\dot{Z}_{b 3}\right. \\
& \left.\quad+\dot{Z}_{w 4}-\dot{Z}_{b 4}\right)-K_{s}\left(Z_{w 1}-Z_{b 1}+Z_{w 2}-Z_{b 2}+Z_{w 3}\right. \\
& \left.\quad-Z_{b 3}+Z_{w 4}-Z_{b 4}\right)=0 \\
& I_{y} \ddot{\theta}-b\left[C_{s}\left(\dot{Z}_{w 3}-\dot{Z}_{b 3}+\dot{Z}_{w 4}-\dot{Z}_{b 4}\right)+K_{s}\left(Z_{w 3}\right.\right. \\
& \left.\left.\quad-Z_{b 3}+Z_{w 4}-Z_{b 4}\right)\right]+a\left[C _ { s } \left(\dot{Z}_{w 1}-\dot{Z}_{b 1}+\dot{Z}_{w 2}\right.\right. \\
& \left.\left.\quad-\dot{Z}_{b 2}\right)+K_{s}\left(Z_{w 1}-Z_{b 1}+Z_{w 2}-Z_{b 2}\right)\right]-m_{b} h g \theta \\
& \quad=0 \\
& I_{x} \ddot{\varphi}-t_{w}\left[C _ { s } \left(\dot{Z}_{w 1}-\dot{Z}_{b 1}-\dot{Z}_{w 2}+\dot{Z}_{b 2}+\dot{Z}_{w 3}-\dot{Z}_{b 3}\right.\right. \\
& \left.\quad-\dot{Z}_{w 4}+\dot{Z}_{b 4}\right)+K_{s}\left(Z_{w 1}-Z_{b 1}-Z_{w 2}+Z_{b 2}+Z_{w 3}\right. \\
& \left.\left.\quad-Z_{b 3}-Z_{w 4}+Z_{b 4}\right)\right]-m_{b} h g \varphi=0 \\
& m_{w 1} \ddot{Z}_{w 1}-C_{s}\left(\dot{Z}_{b 1}-\dot{Z}_{w 1}\right)-C_{t}\left(\dot{Z}_{g 1}-\dot{Z}_{w 1}\right) \\
& \quad-K_{s}\left(Z_{b 1}-Z_{w 1}\right)-K_{t}\left(Z_{g 1}-Z_{w 1}\right)=0
\end{aligned}
$$




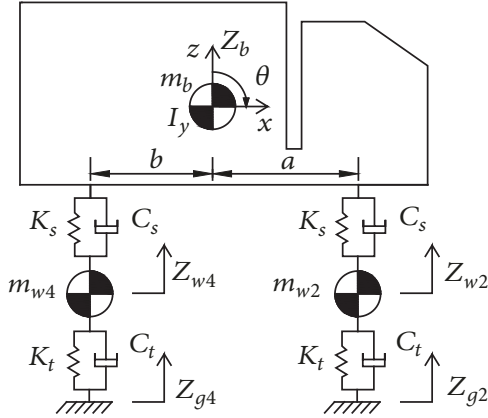

(a)

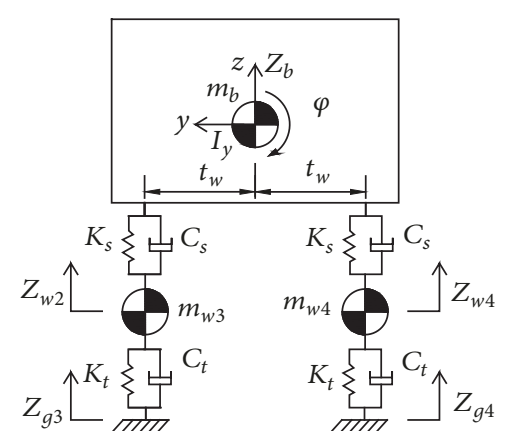

(b)

Figure 1: Simplified vehicle model with 7 DOFs: (a) side view and (b) back view.

$$
\begin{gathered}
m_{w 2} \ddot{Z}_{w 2}-C_{s}\left(\dot{Z}_{b 2}-\dot{Z}_{w 2}\right)-C_{t}\left(\dot{Z}_{g 2}-\dot{Z}_{w 2}\right) \\
-K_{s}\left(Z_{b 2}-Z_{w 2}\right)-K_{t}\left(Z_{g 2}-Z_{w 2}\right)=0 \\
m_{w 3} \ddot{Z}_{w 3}-C_{s}\left(\dot{Z}_{b 3}-\dot{Z}_{w 3}\right)-C_{t}\left(\dot{Z}_{g 3}-\dot{Z}_{w 3}\right) \\
-K_{s}\left(Z_{b 3}-Z_{w 3}\right)-K_{t}\left(Z_{g 3}-Z_{w 3}\right)=0 \\
m_{w 4} \ddot{Z}_{w 4}-C_{s}\left(\dot{Z}_{b 4}-\dot{Z}_{w 4}\right)-C_{t}\left(\dot{Z}_{g 4}-\dot{Z}_{w 4}\right) \\
-K_{s}\left(Z_{b 4}-Z_{w 4}\right)-K_{t}\left(Z_{g 4}-Z_{w 4}\right)=0
\end{gathered}
$$

where $m_{b}$ denotes the vehicle body mass; $m_{w i}(i=1,2,3,4)$ is the mass of the $i$ th wheel; $I_{x}, I_{y}$ are the mass moment of inertia of the vehicle body about the $x$-axis, $y$-axis, respectively; $K_{s}, K_{t}$ are the vertical stiffness of each suspension spring and each tire, respectively; $C_{s}, C_{t}$ are the vertical damping coefficient of each suspension damper and each tire, respectively; $a, b$ are the distance between the center of mass of the vehicle and the front and rear axles, respectively; $h$ is the vertical distance between the center of mass of the vehicle and each wheel; $\theta$, $\varphi$ are the angular displacements of the vehicle body about the $y$-axis, $x$-axis, respectively; $Z_{b}$ is the vertical displacement of the vehicle body; $Z_{w i}(i=1,2,3,4)$ is the vertical displacement of the $i$ th wheel; $Z_{g i}(i=1,2,3,4)$ is the road surface height for the contact position of the $i$ th tire (equal to the sum of the surface roughness height and the deformation of the bridge deck); $Z_{b i}(i=1,2,3,4)$ is the vertical displacement for the $i$ th connection position of the suspension and the vehicle body. Assuming $\theta, \varphi$ to be small, $Z_{b i}(i=1,2,3,4)$ can be expressed as

$$
\begin{aligned}
& Z_{b 1}=Z_{b}+t_{w} \varphi-a \theta \\
& Z_{b 2}=Z_{b}-t_{w} \varphi-a \theta \\
& Z_{b 3}=Z_{b}+t_{w} \varphi+b \theta \\
& Z_{b 4}=Z_{b}-t_{w} \varphi+b \theta
\end{aligned}
$$

$\boldsymbol{X}=\left[\begin{array}{llllllllllllll}\varphi & \theta & Z_{b} & Z_{w 1} & Z_{w 2} & Z_{w 3} & Z_{w 4} & \dot{\varphi} & \dot{\theta} & \dot{Z}_{b} & \dot{Z}_{w 1} & \dot{Z}_{w 2} & \dot{Z}_{w 3} & \dot{Z}_{w 4}\end{array}\right]^{\mathrm{T}}$

$\boldsymbol{M}=\operatorname{diag}\left[\begin{array}{llllllllllllllll}1 & 1 & 1 & 1 & 1 & 1 & 1 & I_{x} & I_{y} & m_{b} & m_{w 1} & m_{w 2} & m_{w 3} & m_{w 4}\end{array}\right]$ where $t_{w}$ is the half of the distance between the left and right wheels.

In order to analyze the bridge and vehicle responses when the vehicle is travelling with varied speed, the assumption that the vehicle speed is constant when passing the bridge is abandoned. The vehicle travelling acceleration is assumed to be $a_{x}$. Equation (1b) is then rewritten as

$$
\begin{aligned}
I_{y} \ddot{\theta} & -b\left[C_{s}\left(\dot{Z}_{w 3}-\dot{Z}_{b 3}+\dot{Z}_{w 4}-\dot{Z}_{b 4}\right)\right. \\
& \left.+K_{s}\left(Z_{w 3}-Z_{b 3}+Z_{w 4}-Z_{b 4}\right)\right] \\
& +a\left[C_{s}\left(\dot{Z}_{w 1}-\dot{Z}_{b 1}+\dot{Z}_{w 2}-\dot{Z}_{b 2}\right)\right. \\
& \left.+K_{s}\left(Z_{w 1}-Z_{b 1}+Z_{w 2}-Z_{b 2}\right)\right]-m_{b} h g \theta+m_{b} h a_{x} \\
& +F_{d} h=0
\end{aligned}
$$

where $F_{d}$ is the air resistance force, related to the vehicle speed, and can be written as [15]

$$
F_{d}=0.5 \rho C_{d} A_{x} V^{2}
$$

where $\rho$ is the air density; $C_{d}$ is the air resistance coefficient; $A_{x}$ is the vehicle windward area.

In order to solve the motion equations of the vehicle by using the built-in solver in Simulink, the vehicle equation should be written in the form of state space. For this purpose, the vehicle motion equation ((1a)-(1g)) is rewritten in the following matrix form:

$$
M \dot{X}=N X+P U
$$

where 
$\boldsymbol{U}=\left[\begin{array}{llllllllll}a_{x} & F_{d} & Z_{g 1} & Z_{g 2} & Z_{g 3} & Z_{g 4} & \dot{Z}_{g 1} & \dot{Z}_{g 2} & \dot{Z}_{g 3} & \dot{Z}_{g 4}\end{array}\right]^{\mathrm{T}}$

$N$

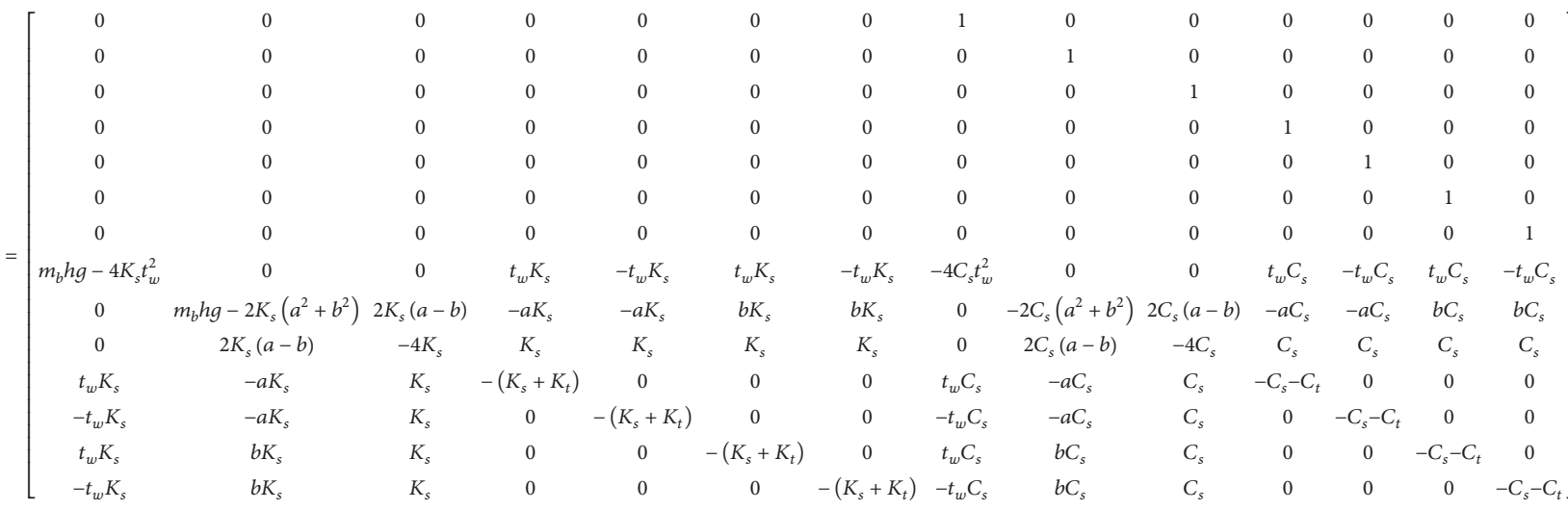

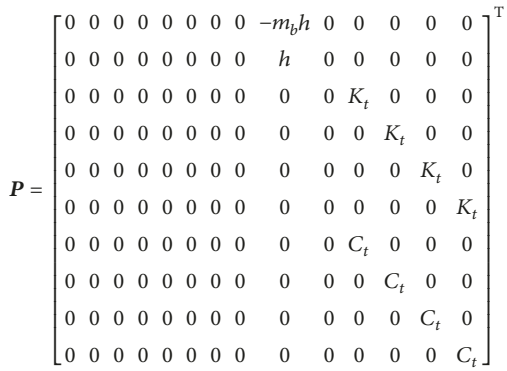

Equation (5) can then be rewritten in the form of the input equation of state apace as

$$
\dot{X}=A X+B U
$$

where

$$
\begin{aligned}
& A=M^{-1} N \\
& B=M^{-1} P
\end{aligned}
$$

State equation of the vehicle (7) can be easily modeled and solved using Simulink to get the state vector of the vehicle $\boldsymbol{X}$.

2.2. Bridge Subsystem. Based on the finite element method, the motion equation of the bridge can be written as

$$
M_{b} \ddot{Z}_{b}+C_{b} \dot{Z}_{b}+K_{b} Z_{b}=F_{v b}
$$

where $Z_{b}, \dot{Z}_{b}$, and $\ddot{Z}_{b}$ are the displacement, velocity, and acceleration vectors of the bridge nodes; $\boldsymbol{M}_{\boldsymbol{b}}, \boldsymbol{C}_{\boldsymbol{b}}$, and $\boldsymbol{K}_{\boldsymbol{b}}$ are the mass matrix, damping matrix, and stiffness matrix of the bridge model; $\boldsymbol{F}_{\boldsymbol{v} b}$ is the load vector from the vehicle tires. Rayleigh damping is assumed for the bridge.

Road roughness is one of the important factors that affect the vibration of the coupling vehicle-bridge system, which not only affects the driving comfort and safety of the vehicle, but also aggravates the dynamic response of the bridge, so it is necessary to consider the road roughness on the bridge deck. A road surface profile can be assumed as a random process in space, and the actual profiles are usually not identical for the left and right wheel paths [16]. Here, an exponentially decreasing model recommended by Bogsjo [17] is used to consider the lateral coherence between the left and right wheel paths:

$$
\gamma_{e}(\Omega)=\exp \left(-\rho_{r} d_{w} \Omega\right)
$$

where $\Omega$ is the spatial frequency of road surface; $\gamma_{e}(\Omega)$ is the coherence coefficient for $\Omega ; d_{w}$ is the lateral distance between the left and right wheel paths; $\rho_{r}$ is a parameter and taken as 4.

The spectral representation method proposed by Shinozuka [18] is used in this paper to simulate the road surface with roughness. For a road surface, $X$ represents the moving direction of the vehicle and $Y$ represents the lateral direction. The lateral width of the road is divided into $N_{l}$ segments. The road surface height at the $j$ th segment at $X$ can be expressed as

$$
\begin{aligned}
& r_{j}(X) \\
& =\sqrt{2(\Delta \Omega)} \sum_{m=1}^{j} \sum_{k=1}^{N_{\Omega}} \sqrt{G\left(\Omega_{m k}\right)} R\left(\Omega_{m k}\right) \cos \left(\Omega_{m k}+\emptyset_{m k}\right) \\
& \Omega_{m k}=(k-1) \Delta \Omega+\frac{m}{N_{l}} \Delta \Omega \\
& R\left(\Omega_{m k}\right) \\
& = \begin{cases}0 & 1 \leq j<m \leq N_{l} \\
\gamma_{e}\left(\Omega_{m k}\right)^{|j-m|} & m=1, m \leq j \leq N_{l} \\
\gamma_{e}\left(\Omega_{m k}\right)^{|j-m|} \sqrt{1-\gamma_{e}\left(\Omega_{m k}\right)^{2}} & 2 \leq m \leq j \leq N_{l}\end{cases}
\end{aligned}
$$




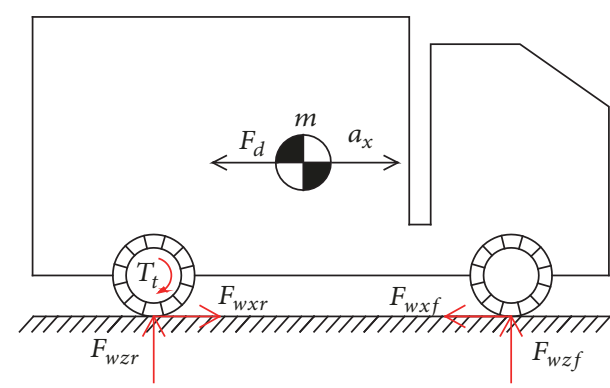

(a)

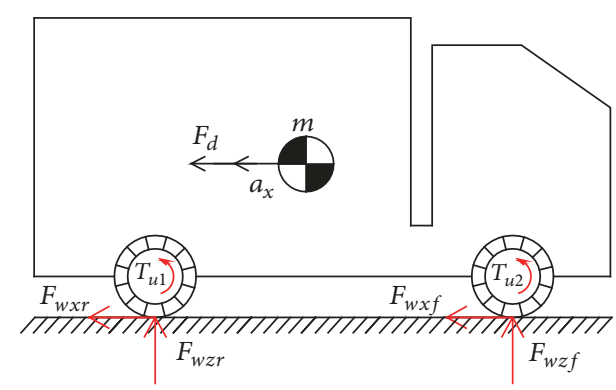

(b)

FIGURE 2: Forced status of vehicle in longitudinal direction: (a) acceleration and (b) braking.

where $\Delta \Omega$ is the interval of spatial frequency of the road surface; $N_{\Omega}$ is the total number of selected frequencies; $\phi_{m k}$ is the phase corresponding to $\Omega_{m k}$, which is considered as a random phase angle distributed from 0 to $2 \pi ; G\left(\Omega_{m k}\right)$ is the PSD function that can be expressed as [19]

$$
G(\Omega)=G\left(\Omega_{0}\right)\left(\frac{\Omega}{\Omega_{0}}\right)^{-2} \quad\left(\Omega_{1}<\Omega<\Omega_{2}\right)
$$

where $\Omega_{0}$ is the reference spatial frequency of road surface, and $\Omega_{0}=0.1 \mathrm{~m}^{-1} ; G\left(\Omega_{0}\right)$ is the roughness coefficient whose value is chosen depending on the road condition such as Classes A, B, and C; $\Omega_{1}$ and $\Omega_{2}$ are the lower and upper cut-off frequencies, respectively. The vehicle moves on the simulated road surface, and the coherence between the road surface profiles for the left and right wheels can be considered.

\subsection{Tire Forces under Acceleration and Braking. The vehicle-} bridge system has been divided into the bridge subsystem and the vehicle subsystem. The dynamic equations of these two subsystems also have been established above. The road roughness is a type of excitation on the vehicle and also can be regarded as a moving boundary for the vehicle tires. Meanwhile, vehicle tires transmit the interaction forces between the two subsystems. Assuming that the tires are in touch with the bridge deck all through the process of passing the bridge, the vertical tire forces $F_{w z i}$ can be calculated as (13) regarding the tire to be linearly elastic [4].

$$
F_{w z i}=K_{t}\left(Z_{b i}+r_{i}-Z_{w i}\right)+C_{t}\left(\dot{Z}_{b i}-\dot{Z}_{w i}\right)
$$

where $i$ is the number of the tire; $r_{i}$ is the road roughness height of the contact position between the $i$ th tire and the bridge deck; $Z_{b i}, \dot{Z}_{b i}$ are the vertical displacement and velocity of the bridge deck at the corresponding contact position and can be interpolated from the nodal values in the dynamic results of the finite element model of the bridge.

In order to investigate the effects of varied vehicle speed on the dynamic responses, it is necessary to perform force analysis to get the tire forces in the longitudinal direction. Assuming that the wheels on the front wheels are driven wheels and the rear wheels are driving wheels, Figure 2 shows the vehicle model that takes into account the longitudinal forces. When the vehicle is being braked (Figure 2(b)), both the front and rear wheels bear the braking torques $\left(T_{u 1}\right.$ and $\left.T_{u 2}\right)$. And the longitudinal tire forces of the front and rear wheels are opposite to the moving direction and should be calculated according to the braking force distribution coefficient $\beta$ [20]. $\beta$ is defined as the ratio of the longitudinal force of the front wheel to the total longitudinal force:

$$
\beta=\frac{F_{w x f}}{F_{w x f}+F_{w x r}}
$$

where $F_{w x f}, F_{w x r}$ are the total longitudinal tire forces of the front and the rear wheel, respectively.

Based on the longitudinal motion equilibrium condition, the equilibrium force equation for braking can be written as

$$
m a_{x}=F_{w x f}+F_{w x r}+F_{d}
$$

where $m$ is the total mass of the vehicle.

Based on (14) and (15), the longitudinal tire forces for the front wheel and the rear wheel during braking can be solved as

$$
\begin{aligned}
& F_{w x f}=\beta\left(m a_{x}-F_{d}\right) \\
& F_{w x r}=(1-\beta)\left(m a_{x}-F_{d}\right)
\end{aligned}
$$

When the vehicle is speeding up (Figure 2(a)), the effects of the longitudinal tire forces on the driving wheel and the driven wheel are different [20]. The longitudinal tire forces on the driving wheels are the same as the moving direction. The driven wheels do not bear the driving torque of engine, and the longitudinal tire forces between the driven wheels and the road surface can be considered to be the tire rolling resistance and are opposite to the moving direction, which can be written as

$$
F_{w x f}=f_{R} F_{w z f}
$$

where $f_{R}$ is the tire rolling resistance coefficient, generally increasing with the rising of the vehicle speed. $f_{R}$ is usually determined by experiments. As there is a lack of experimental data, the following empirical formula can be used to estimate the tire rolling resistance coefficient [21]:

$$
f_{R}=f_{0}\left(1+\frac{V^{2}}{19400}\right)
$$


where $V$ is the vehicle speed in $\mathrm{km} / \mathrm{h} ; f_{0}$ is a standard value of the tire rolling resistance coefficient, which is independent to the vehicle speed.

Based on the longitudinal motion equilibrium condition, the longitudinal tire force for the rear wheel during speeding up can be written as

$$
F_{w x r}=m a_{x}+F_{w x f}+F_{d}
$$

It should be pointed out that there is an extreme value of $a_{x}$ during braking due to the limitation of the static friction between the tires and the road surface. That is to say, if the longitudinal tire force reaches the limit of static friction, the tire will slip on the road surface. Assuming the longitudinal tire forces of left and right wheel on the same axle have the same magnitude, the corresponding friction limit condition in the braking process can be expressed as

$$
\begin{aligned}
\frac{1}{2} \beta\left(m a_{x}-F_{d}\right) & =\mu F_{w z f i} \\
\frac{1}{2}(1-\beta)\left(m a_{x}-F_{d}\right) & =\mu F_{w z r j}
\end{aligned}
$$

where $\mu$ is the static friction coefficient between the tire and the road surface; $F_{w z f i}, F_{w z r j}$ are the vertical forces on the $i$ th tire of the front wheel axle and the $j$ th tire of the rear wheel axle, respectively. Therefore, the maximum deceleration becomes

$$
\begin{aligned}
& a_{x}^{m} \\
& =\min _{i, j}\left[\frac{1}{m}\left(\frac{2 \mu}{\beta} F_{w z f i}+F_{d}\right), \frac{1}{m}\left(\frac{2 \mu}{1-\beta} F_{w z r j}+F_{d}\right)\right]
\end{aligned}
$$

In the acceleration process, the corresponding friction limit condition for the $i$ th front tire can be expressed based on (17) and (18) as

$$
f_{0}\left(1+\frac{V^{2}}{19400}\right) F_{w z f i}=\mu F_{w z f i}
$$

Thus, the friction limit of the front wheel is controlled by the vehicle speed with

$$
V^{m}=\sqrt{19400\left(\frac{\mu}{f_{0}}-1\right)}
$$

The corresponding friction limit condition for the $j$ th rear tire can be expressed as

$$
\frac{1}{2}\left(m a_{x}+F_{w x f}+F_{d}\right)=\mu F_{w z r i}
$$

Therefore, the maximum acceleration is

$$
\begin{aligned}
a_{x}^{m} & =\min _{j}\left[\frac { 1 } { m } \left(2 \mu F_{w z r j}-F_{d}\right.\right. \\
& \left.\left.-\sum_{i} f_{0}\left(1+\frac{V^{2}}{19400}\right) F_{w z f i}\right)\right]
\end{aligned}
$$

\section{Solving Procedure and Verification}

3.1. Solving Procedure on Combination of SIMULIK and ANSYS. When solving VBI using the iterative method for the bridge subsystem and the vehicle subsystem, some traditional methods, such as Newmark method and Wilson method, are frequently used to solve the dynamic equations. Sophisticated codes usually are developed to achieve the numerical solutions. However, these in-house programs usually have limited functions and are difficult to make user-friendly interface or be available to wider user communities compared with typical commercial software packages. To this end, this paper is to use the combination of the generally available commercial software ANSYS and Simulink to solve the vehicle-bridge interaction problems. Both of ANSYS and Simulink are popular in their fields for finite element modeling and the mathematic modeling and solving. In the VBI system, the vehicle subsystem can be simulated as a numerical model in Simulink while the bridge subsystem can be modeled in ANSYS. The interaction between the two subsystems can be easily realized through the so-called inter-history iteration method proposed by Zhang and Xia [4]. The preparation and solving procedure is summarized as follows.

\section{(1) Preparation}

(a) According to the motion equation of the vehicle, the corresponding vehicle model is established in state space using Simulink. The core is to solve the motion equation (7) in state space, and the fourth-order Runge-Kutta method in the built-in solver of Simulink is chosen as the solution scheme. For the vehicle model, the input data is the road surface excitation including the vertical displacement and velocity of the bridge deck and the road roughness. After solving of the motion equations, the vehicle responses including the time histories of the tires' positions are the output. Meanwhile, the vertical and longitudinal tire forces are calculated in Simulink as described in Section 2.3.

(b) By using ANSYS Parameter Design Language (APDL), a program for solving the bridge subsystem is compiled with the following functions: (1) establishing the finite element model of the target bridge; (2) reading the time history data of the tire positions, the vertical tire forces, and the longitudinal tire forces solved by Simulink; (3) checking whether the tires are on the bridge deck at each time step. If yes, apply the tire forces on the bridge model and then solve the motion equations of the bridge referred to in Section 2.2 using the transient analysis in ANSYS.

(c) Based on the Matlab platform, a main program is written to call the vehicle solution model in Simulink and the bridge solution model in ANSYS. In this way, the iterative solving procedure can be executed automatically.

\section{(2) Solving Procedure}

(a) Firstly, without consideration of the bridge deformation, the main program starts to call Simulink and solve the vehicle's motion equations. The time histories of the tire positions, the vertical tire forces, and the longitudinal tire forces can be obtained, as well. Then, the outputs of these data are stored in a file to be read directly by ANSYS. 
(b) Secondly, the main program will call and run ANSYS for analyzing the bridge subsystem. The tire forces are loaded from the data file in step (a) and applied on the bridge model. After solving the motion equation of the bridge, the time histories of the nodal displacements of the bridge at the contact points between tires and the bridge deck can be obtained and exported to a file which can be read by Simulink.

(c) Thirdly, the moving boundary of the tires is updated by superimposing the nodal displacements of the bridge and the road roughness height. Then Simulink runs again to solve the vehicle motion equation and the time history of the tire forces can be obtained. The convergence criteria of the iterative process are defined based upon the differences of the tire forces between the two adjacent iterations. If the differences are within the threshold, the calculation will end; otherwise, step (b) and step (c) will be repeated until the convergence condition is met.

3.2. Numerical Verification. In order to verify the proposed method, a typical vehicle-bridge interaction example under two simulation conditions introduced by Yang and $\mathrm{Wu}$ [5] is studied in this section. In the first condition, the vehicle passes the bridge with a constant speed of $27.78 \mathrm{~m} / \mathrm{s}$. The longitudinal tire forces are ignored to verify the vertical vibration. In the second condition, the vehicle brakes on the bridge with an initial speed of $50 \mathrm{~m} / \mathrm{s}$ and a deceleration of $-10 \mathrm{~m} / \mathrm{s}^{2}$. The longitudinal tire forces are taken into account to verify the longitudinal effects of longitudinal forces. According to Yang and $\mathrm{Wu}$ [5], the vehicle model is set up with 2 DOFs to pass on a simply supported beam. The key parameters of the simply supported beam include span length $L=30 \mathrm{~m}$, section inertia moment $I=8.65 \mathrm{~m}^{4}$, elastic modulus $E=2.943 \mathrm{E} 10 \mathrm{~N} / \mathrm{m}^{2}$, mass per unit length $\rho=36000 \mathrm{~kg} / \mathrm{m}$, Poisson ratio $v=0.2$, and damping ratio $\xi=0$. The parameters of the vehicle model are adopted as mass of the vehicle body $M_{v}=5.4 \mathrm{E} 5 \mathrm{~kg}$, mass moment of inertia of the vehicle body $I_{v}=1.38 \mathrm{E} 7 \mathrm{~kg} \cdot \mathrm{m}^{2}$, stiffness of the suspension spring $k_{v}=4.135 \mathrm{E} 7 \mathrm{~N} / \mathrm{m}$, tire mass $M_{w}=0 \mathrm{~kg}$, and wheel-to-wheel distance $d=17.5 \mathrm{~m}$.

Under the first simulation condition, the vertical displacement of the midpoint of the simply supported beam and the vertical acceleration of the vehicle body are plotted in Figures 3-4, along with the solutions given by Yang and $\mathrm{Wu}[5]$. As shown in the figures, good agreement has been achieved for both the vehicle responses and the bridge responses. Under the second condition (braking), $-10 \mathrm{~m} / \mathrm{s}^{2}$ deceleration already exceeded the friction limitation of tires, and the longitudinal forces are simplified with the product of the friction coefficient and the vertical tire force. The vertical displacement of the midpoint of the simply supported beam, the vertical acceleration of the vehicle body, and the horizontal reaction force occurring at the hinged support are plotted in Figures 5-7, respectively. In Figures 5-7, Present case 1 means the results under the proposal vehicle model, while Present case 2 represents the model used in Yang and $\mathrm{Wu}$ [5]. The nondimensional value $x / L$, where $x$ is the vehicle position, is adopted as the independent variable of the results. As can be seen, if using the model in Yang and $\mathrm{Wu}$ [5], the results have a good agreement. As also can be seen, obvious

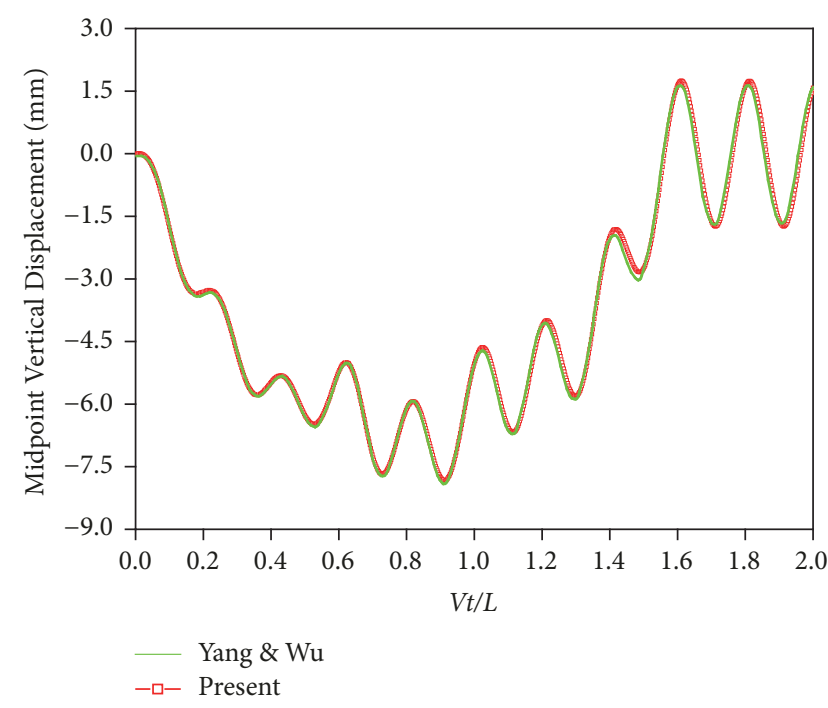

FIGURE 3: Vertical displacement of midpoint of simply supported beam.

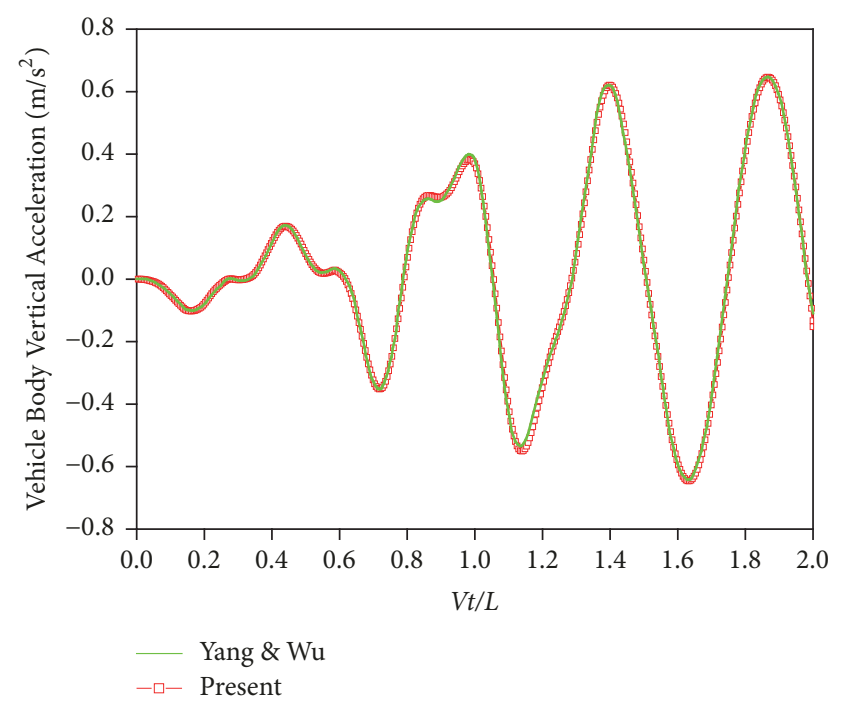

FIGURE 4: Vertical acceleration of vehicle body.

differences exist between the results obtained by the proposed approach (Present, case 1) and these given in [5]. The reason is the effect of vehicle acceleration on the pitching motion of the vehicle. This effect is very obvious on the first $0.6 \mathrm{~L}$ in Figure 7, where the vehicle acceleration brings out a vertical tire force transform and is explained in Section 4.2.

\section{Dynamic Results Analysis considering Varied Vehicle Speed}

Based on the method proposed in this paper, a simply supported beam subjected to a moving vehicle is studied. The vehicle parameters are adopted according to [22]. The key parameters of the simply supported beam are as follows: span length $L=25 \mathrm{~m}$, section inertia moment $I=2.90 \mathrm{~m}^{4}$, elastic modulus $E=2.87 \mathrm{E} 9 \mathrm{~N} / \mathrm{m}^{2}$, mass per unit length $\rho=2303 \mathrm{~kg} / \mathrm{m}$, 


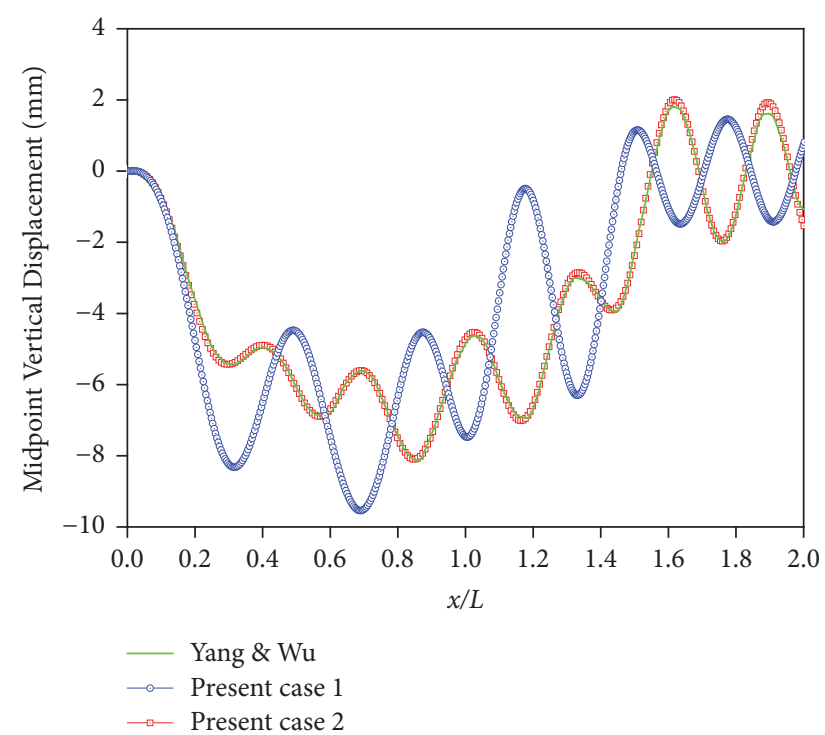

FigURE 5: Vertical displacement of midpoint of simply supported beam.

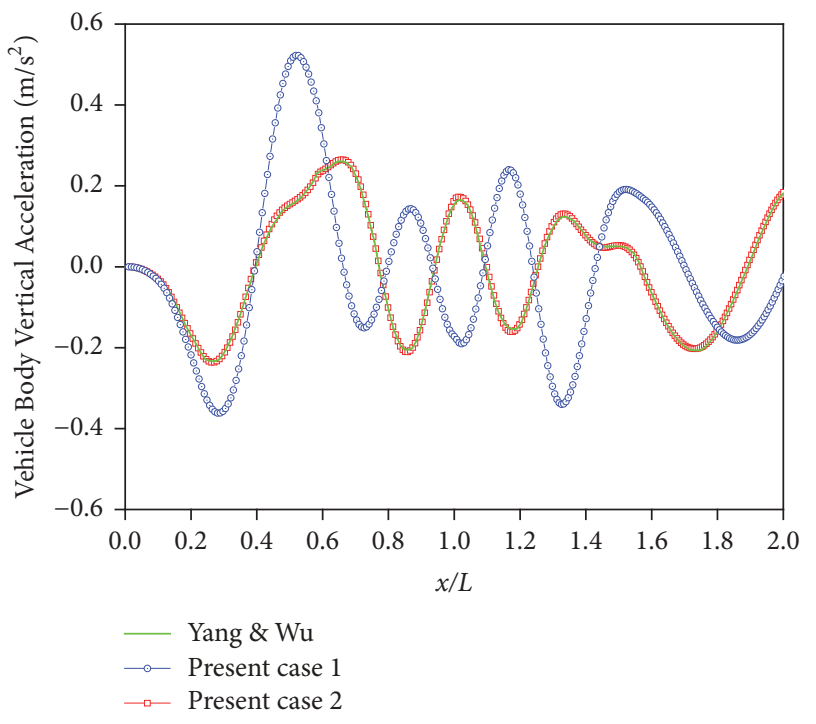

FIGURE 6: Vertical acceleration of vehicle body.

and Poisson ratio $v=0.2$. The time step adopted by Simulink and ANSYS is $0.005 \mathrm{~s}$. For the air resistance force in (4), the air density $\rho=1.225 \mathrm{~kg} / \mathrm{m}^{3}$, the air resistance coefficient $C_{d}=0.8$, and the vehicle windward area $A_{x}=6 \mathrm{~m}^{2}$. For the tire rolling resistance coefficient in (18), the standard value $f_{0}=0.014$. For the braking force distribution coefficient in (16a) and (16b), $\beta=0.64$. For these selected parameters, the estimated values of the maximum acceleration in the acceleration process and braking process at the speed of $60 \mathrm{~km} / \mathrm{h}$ can be estimated based on the static vertical tire forces as $2.8 \mathrm{~m} / \mathrm{s}^{2}$ and $8.0 \mathrm{~m} / \mathrm{s}^{2}$, respectively.

4.1. Constant Vehicle Speed. The dynamic performances of the vehicle passing the bridge with constant speeds are firstly calculated as the references to the cases with varied speeds.

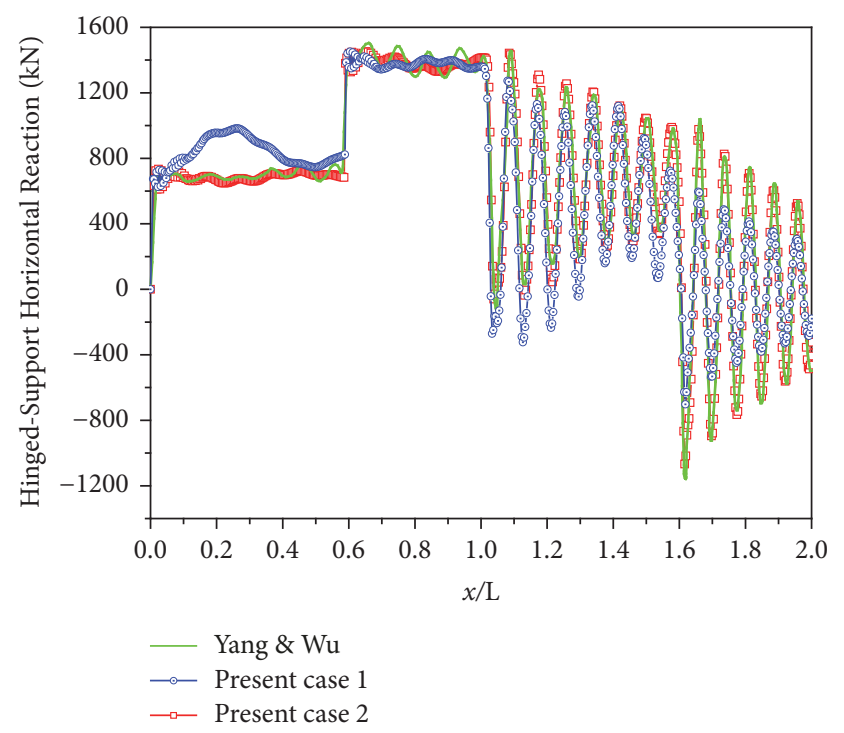

FIgURE 7: Horizontal reaction at hinged support.

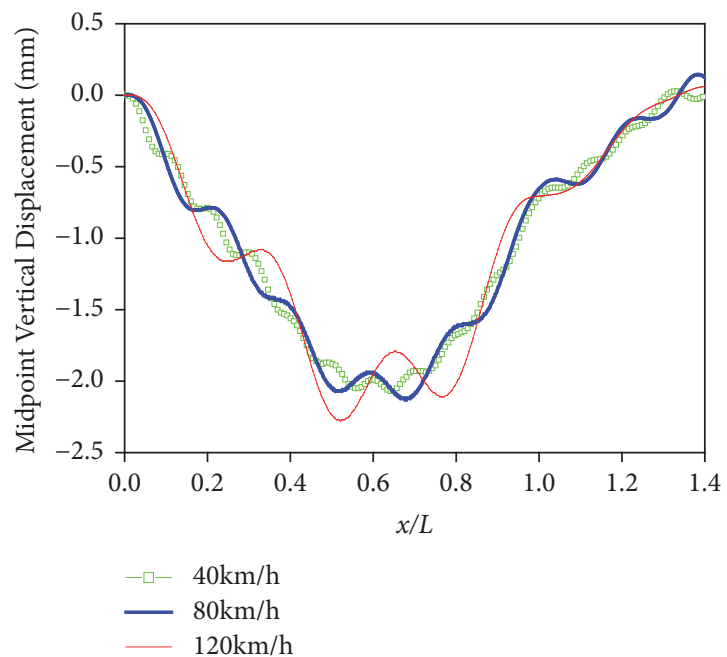

FIgURE 8: Vertical displacement of midpoint of simply supported beam with different speed.

The constant vehicle speeds are considered as $40 \mathrm{~km} / \mathrm{h}$, $80 \mathrm{~km} / \mathrm{h}$, and $120 \mathrm{~km} / \mathrm{h}$, respectively. The bridge damping and road roughness are ignored for a simple and direct comparison. The vertical deflections of the beam at the midpoint for the three constant speeds are plotted in Figure 8. As shown in the figures, the maximum midpoint deflection occurs when the vehicle moves close to the midpoint of the simple supported beam and increases slightly for the high vehicle speed. It is suggested that the increase of the vehicle speed contributes to the amplification of the vertical dynamic responses of the bridge for the current case. Figure 9 shows the vertical acceleration of the vehicle body, from which it can be found that the increase of the vehicle speed also aggravates the vertical dynamic response of the vehicle. 


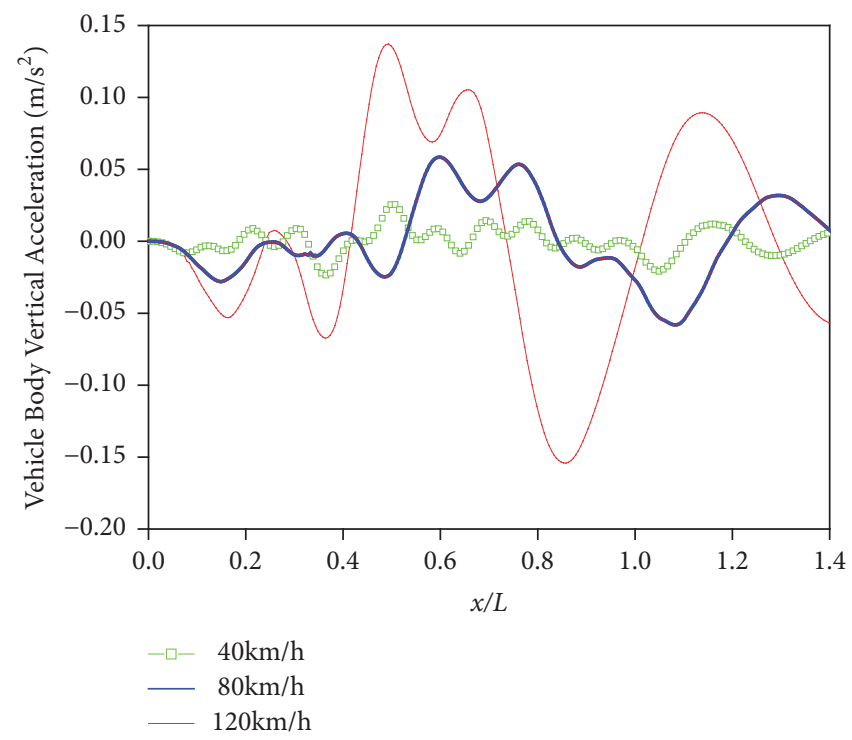

FIGURE 9: Vertical acceleration of vehicle body with different speed.

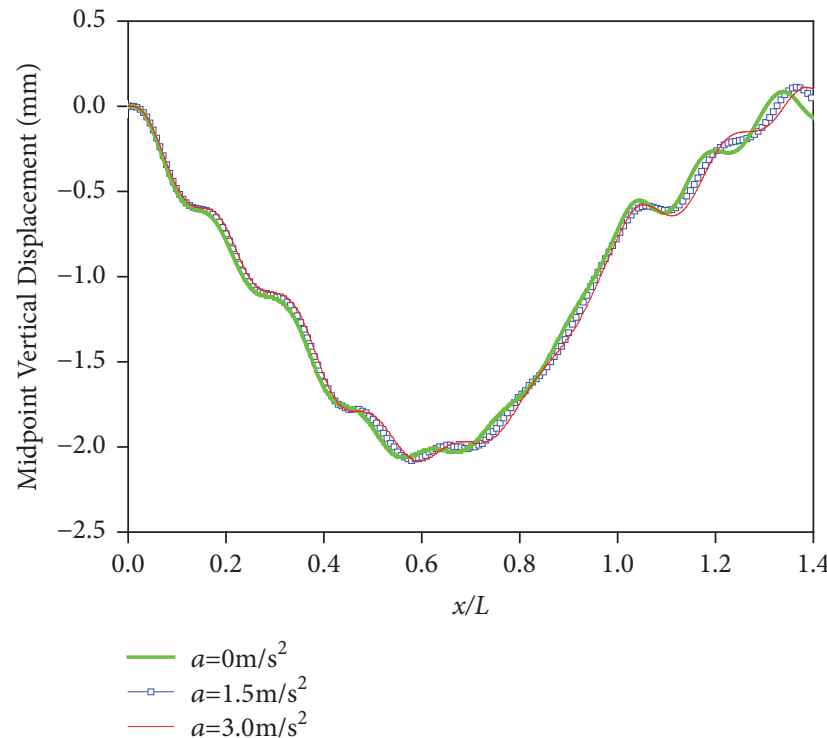

(a) Acceleration

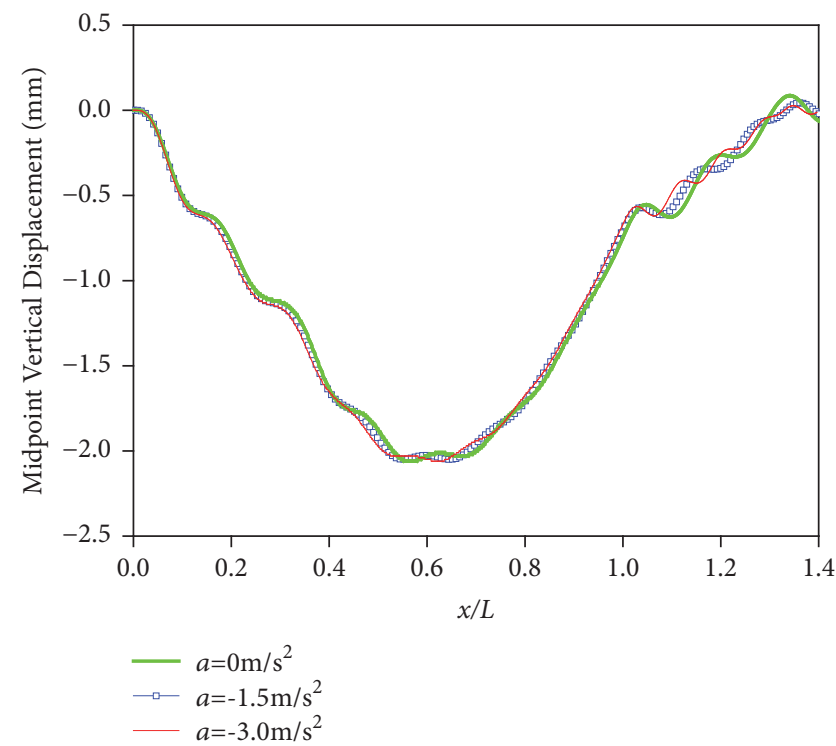

(b) Braking

FIGURE 10: Vertical displacement of midpoint of simply supported beam during varied vehicle speed.

4.2. Varied Vehicle Speed. The dynamic responses of the bridge caused by the vehicle with varied speeds are studied in this section. Assuming that the initial speed of the vehicle is $60 \mathrm{~km} / \mathrm{h}$ and the change of speed begins when the front tires enter on the bridge deck, the vehicle accelerations $a_{x}=1.5 \mathrm{~m} / \mathrm{s}^{2}$ and $3.0 \mathrm{~m} / \mathrm{s}^{2}$ are adopted for acceleration conditions, and $a_{x}=-$ $1.5 \mathrm{~m} / \mathrm{s}^{2}$ and $-3.0 \mathrm{~m} / \mathrm{s}^{2}$ are adopted for braking conditions. In addition, $a_{x}=0 \mathrm{~m} / \mathrm{s}^{2}$ is adopted as a comparison case. The damping ratio of the bridge is adopted as $\xi=0.025$, and the effect of road roughness is ignored.

The vertical deflections of the midpoint of the simply supported beam are plotted in Figure 10. It can be found that the curves are close to each other for both acceleration and braking conditions, which indicates that the varied vehicle speed has limited effect on the vertical displacement of the simply supported beam. This is because the time of vehicle passing through the bridge is very short and the change of the vehicle speed is small, which is not enough to cause an obvious difference of the displacement of the simply supported beam.

The vertical accelerations of the midpoint of the simply supported beam are plotted in Figure 11. P1 represents the time when the rear tires move on the deck, and P2 represents the front tires moving out of the deck. As can be seen, for a period of time (about 0 to $0.1 \mathrm{x} / \mathrm{L}$ ) when the vehicle just entered on the bridge deck, the vertical accelerations of the 


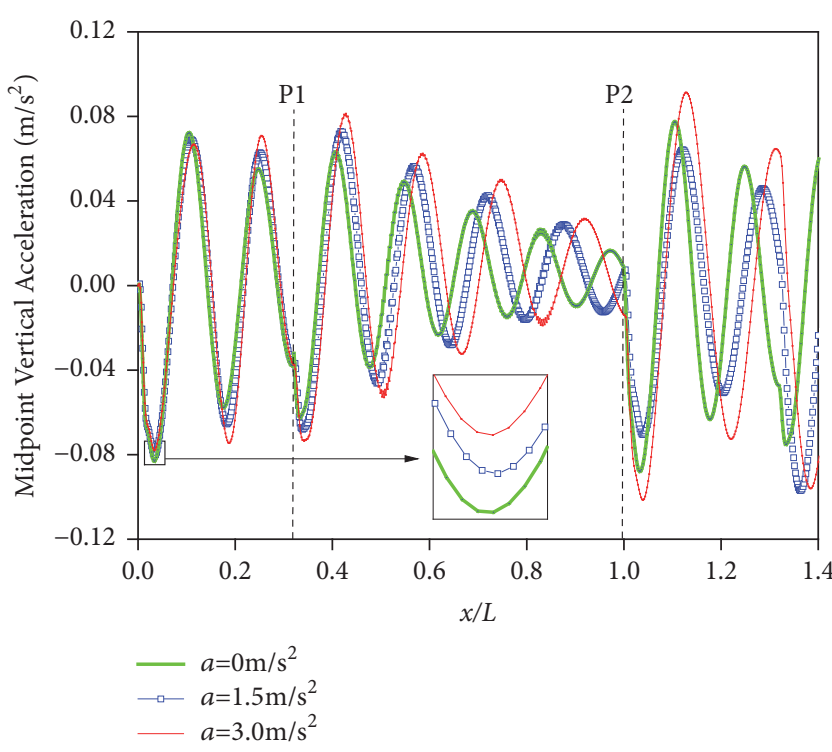

(a) Acceleration

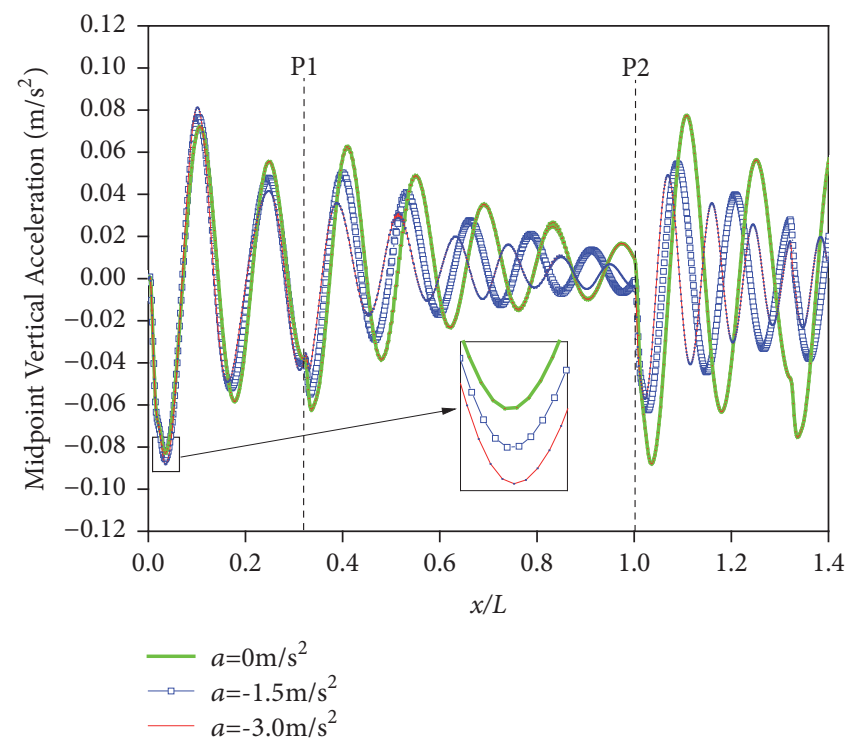

(b) Braking

FIGURE 11: Vertical acceleration of midpoint of simply supported beam during varied vehicle speed.

midpoint of the beam at the acceleration of $3 \mathrm{~m} / \mathrm{s}^{2}$ are slightly lesser than those in the cases at the accelerations of $1.5 \mathrm{~m} / \mathrm{s}^{2}$ and $0 \mathrm{~m} / \mathrm{s}^{2}$. Also during this time period of braking, the vertical accelerations of the midpoint of the beam at $-3 \mathrm{~m} / \mathrm{s}^{2}$ are slightly larger than those at $-1.5 \mathrm{~m} / \mathrm{s}^{2}$ and $0 \mathrm{~m} / \mathrm{s}^{2}$. This is due to the fact that only the front tires act on the beam in this period, and there are different loads that transfer between the front and the rear wheels. During the acceleration, the vertical tire forces transfer from the front wheels to the rear wheels, which cause the vertical tire forces on the front wheels decrease with the increase of the acceleration of the vehicle. During the braking, the vertical tire forces transfer from the rear wheels to the front wheels, which cause the vertical tire forces on the front wheels to increase with the increase of the deceleration of the vehicle. Additionally, as the simulation continues, the difference increases between the vertical accelerations at the midpoint of the beam for the acceleration of $3 \mathrm{~m} / \mathrm{s}^{2}$ and those for the accelerations of $1.5 \mathrm{~m} / \mathrm{s}^{2}$ and $0 \mathrm{~m} / \mathrm{s}^{2}$. This is due to the increasing differences of the vehicle speed among different cases, which has been shown in Section 4.1 that the increase of the vehicle speed will aggravate the vertical dynamic response of the bridge. One more phenomenon is deserved to be pointed out that when the rear wheel enters on the bridge deck or the front wheel leaves the deck, the vertical midpoint acceleration of the beam will have a sudden increase, and the variation of the latter is more obvious than the former. That is caused by the sudden increase or decrease of the load acting on the beam. Since the vertical midpoint acceleration just before the front wheel leaving the beam is relatively small due to the damping effects, sudden increase phenomenon is obviously observed when the front wheel leaves the beam.

Figure 12 shows the vertical accelerations of the vehicle body. It can be observed that a sudden acceleration or braking will cause a sharp change of the vertical acceleration of the vehicle body and the change tendency is contrary to each other. Moreover, the vertical response is larger for the cases with large accelerations or decelerations. That is because a sudden acceleration or braking will cause a pitching motion of the vehicle body, which has direct relation with the vertical motion of the vehicle body, and the angular rotation is larger for high value of vehicle acceleration or deceleration.

Figure 13 depicts the longitudinal reaction force occurring at the hinged support. As can be seen, the horizontal reaction force has an obvious sudden change at the instant when the front wheel or the rear wheel enters or leaves the beam. And the longitudinal reaction forces during varied vehicle speed are far greater than the constant vehicle speed. As illustrated in Section 2.3, the rear wheel is the driving wheel. The longitudinal tire force is mainly distributed on the rear wheel to provide the driving force of the acceleration of the whole vehicle. It is obvious in Figure 13(a) that the longitudinal reaction after the rear tires move on the beam is far greater than that before and in the same direction of the vehicle. For braking, the distributed longitudinal tire forces on the front and rear wheels depend on the braking force distribution coefficient $\beta$ and are opposite to the direction of the vehicle.

4.3. Effects of Road Roughness and Bridge Damping. In order to investigate the effects of road roughness on the dynamic responses, the vehicle passes the bridge with an initial speed of $60 \mathrm{~km} / \mathrm{h}$ and an acceleration $a_{x}=2.5 \mathrm{~m} / \mathrm{s}$. The road surface is generated as discussed in Section 2.2, and the bridge damping ratio is neglected. The vertical midpoint deflection of the beam at the middle point for three different road surface classes is plotted in Figure 14. As can be seen, for the poor road surface, the deflection curves fluctuate more obviously, 


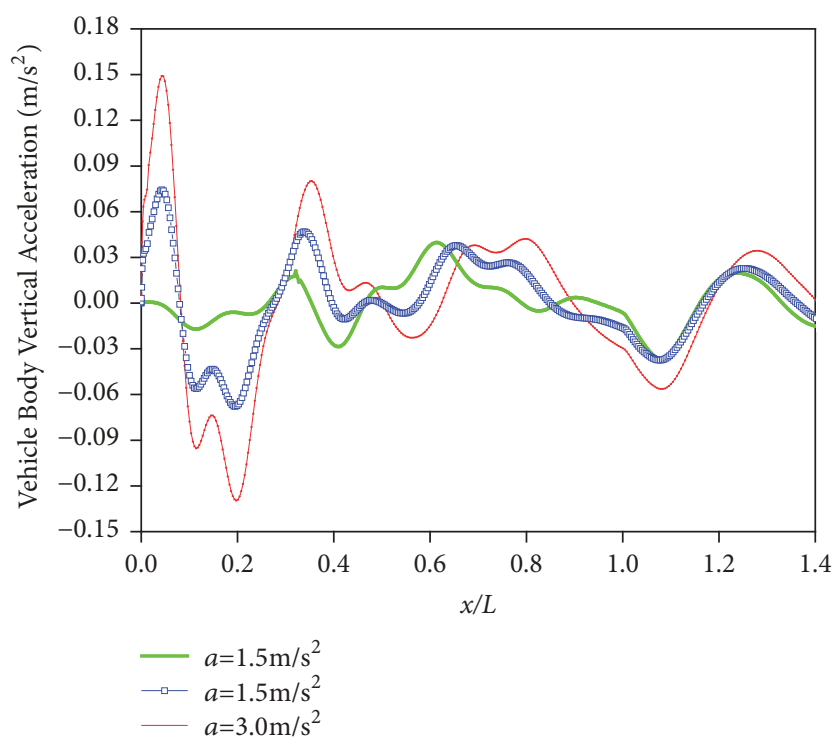

(a) Acceleration

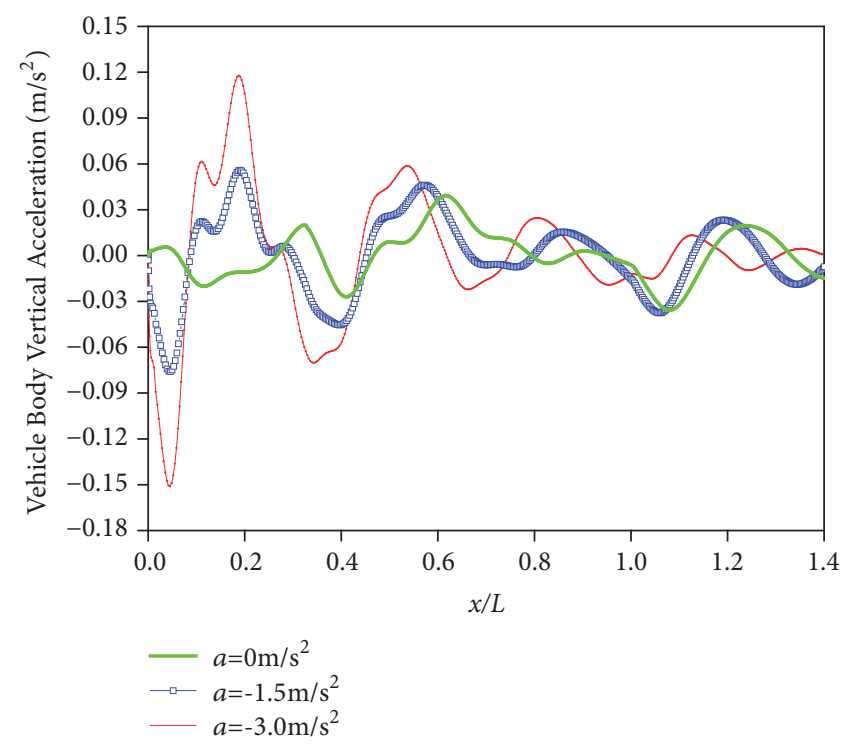

(b) Braking

FIGURE 12: Vertical acceleration of vehicle body during varied vehicle speed.

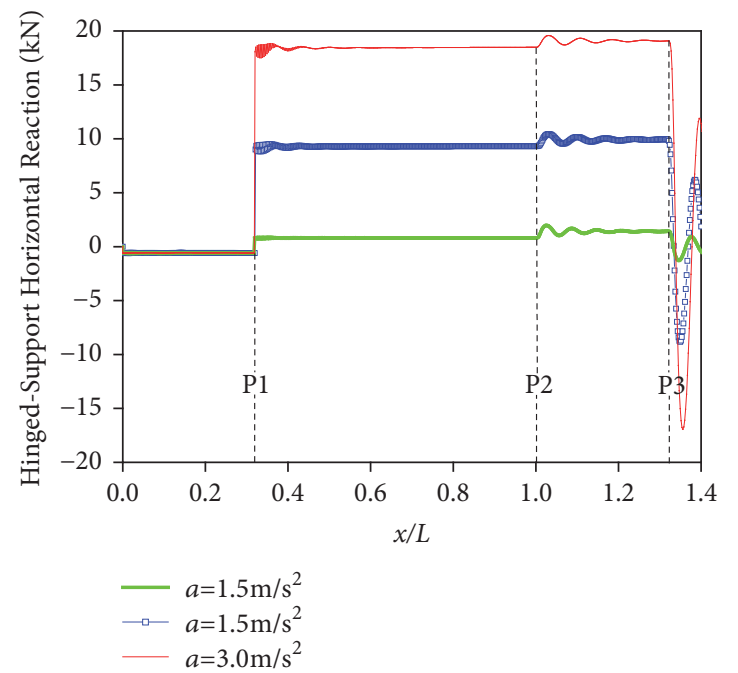

(a) Acceleration

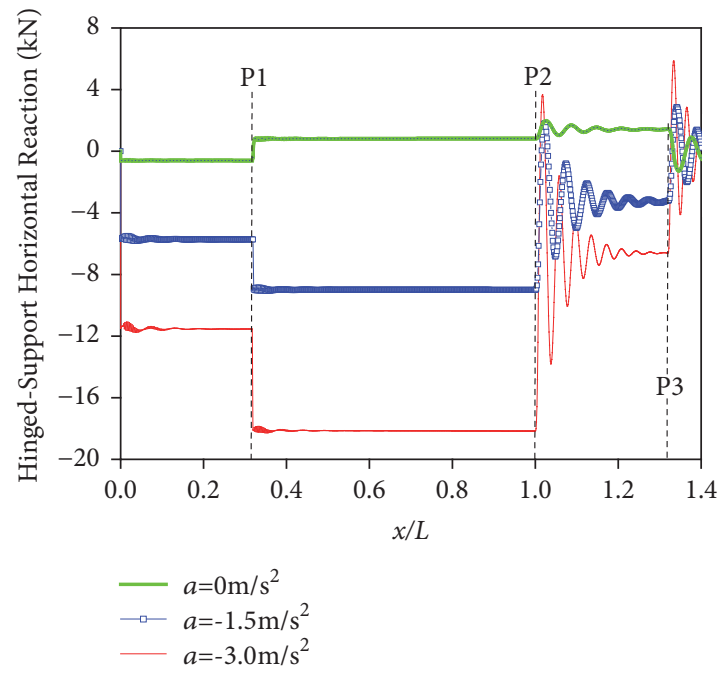

(b) Braking

FIGURE 13: Longitudinal reaction at hinged support of simply supported beam.

which indicates that the poor road surface will contribute to the amplification of the dynamic response of the bridge. Figure 15 shows the vertical acceleration of the vehicle body for three different road surface classes; it can be found that the poor road surface will also aggravate the vertical dynamic response of the vehicle. Figure 16 depicts the longitudinal reaction force occurring at the hinged support, which shows that the road roughness has limited effects on the longitudinal reaction force.

Finally, further discussions focus on the effect of bridge damping on the dynamic responses. Similarly, the vehicle is also assumed to pass the bridge with an initial speed $60 \mathrm{~km} / \mathrm{h}$ and an acceleration $a_{x}=2.5 \mathrm{~m} / \mathrm{s}$. The damping ratios of the bridge are considered as $0,0.025$, and 0.05 , respectively. The effect of road roughness is ignored. The vertical midpoint deflections of the beam for three different bridge damping ratios are plotted in Figure 17. As can be seen, for the smaller damping ratios, the deflection curves fluctuate more obviously, which indicates that the larger damping ratio is advantageous to reduce the dynamic response of the bridge. Figure 18 shows the vertical acceleration of the vehicle body for three different bridge damping ratios from which it can be found that the larger damping ratio is also advantageous to reduce the vertical dynamic response of the vehicle. Figure 19 depicts the longitudinal reaction force occurring at the hinged support, which suggests that the bridge damping 


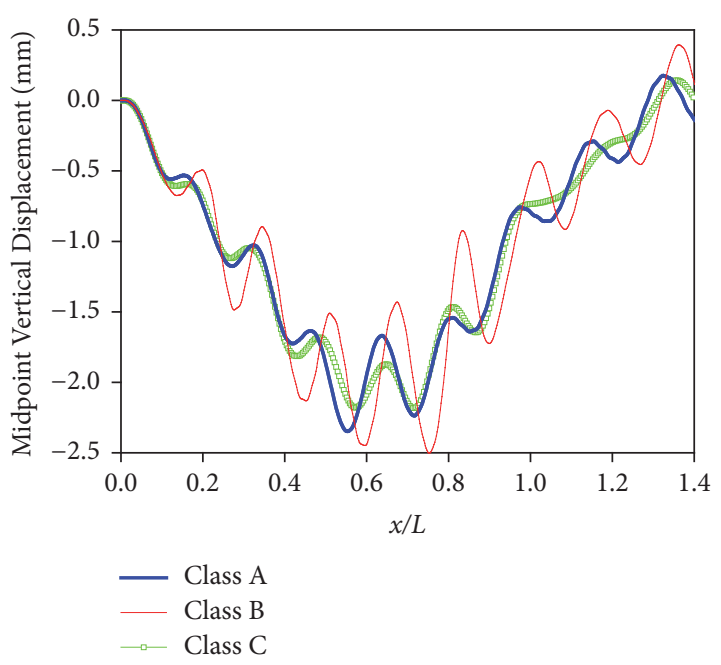

FIGURE 14: Vertical displacement of midpoint of simply supported beam with different roughness class.

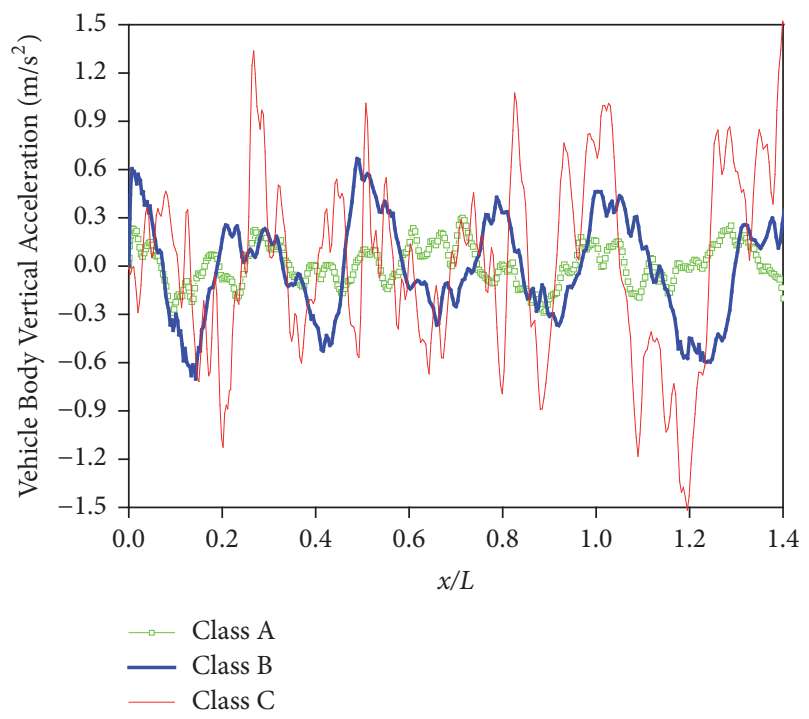

FIGURE 15: Vertical acceleration of vehicle body with different roughness class.

has limited effect on the longitudinal reaction force of the beam.

\section{Conclusions}

A simulation process of analyzing road vehicle-bridge interaction considering varied vehicle speed based on the combination of Simulink and ANSYS has been presented in this paper. The motion equations of the vehicle model are set up in state space and solved in Simulink. The bridge is modeled in the finite element method using ANSYS. A main control program is established to link and communicate the two software packages using temporary data files for the iterations in the simulation process to solve the VBI problem. In this way, the compilation of complex in-house computer programs for typical VBI can be further improved taking

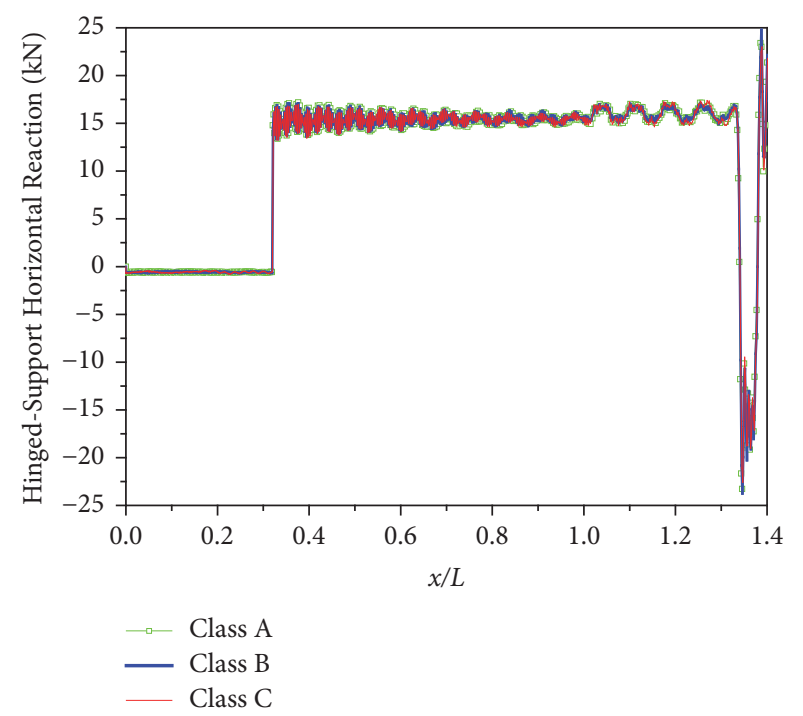

FIGURE 16: Longitudinal reaction at hinged support of simply supported beam with different roughness class.

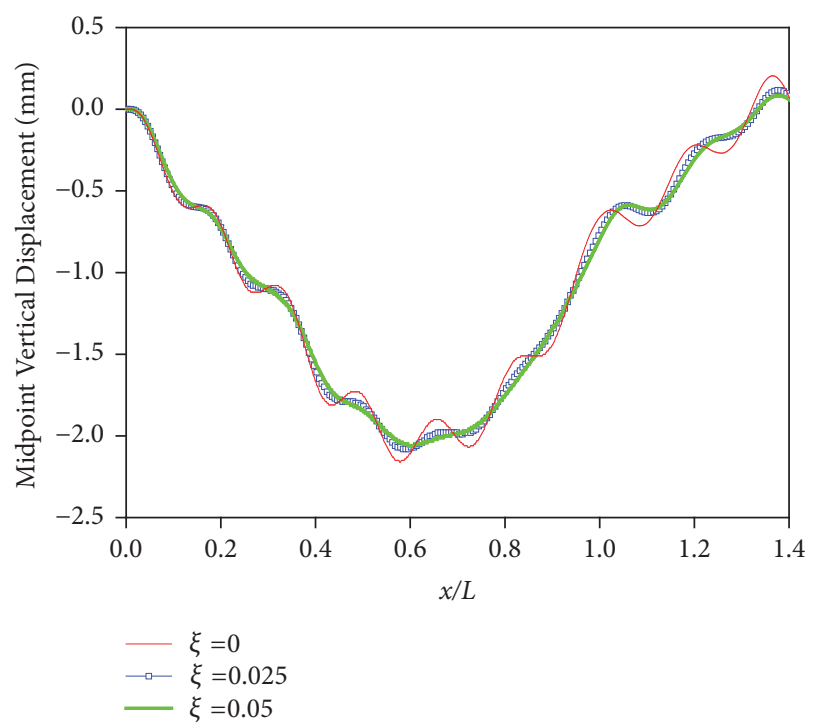

Figure 17: Vertical displacement of midpoint of simply supported beam with different damping.

advantage of available commercial software for finite element modeling and data processing. The proposed procedure and the codes are verified firstly through a widely used example in the literature. After considering the varied vehicle speed, the detailed longitudinal force models between the tires and bridge deck is confirmed. Due to different mechanics mechanism during the acceleration and braking process, the longitudinal force expressions have different forms. Through case studies of a simply supported beam subjected to a moving vehicle with varied speeds, some conclusions can be summarized as follows: (1) The vertical acceleration characteristics of the midpoint of beam can be distinguished into two periods. At first, the front wheels act on the beam and the load transform leads to different vertical tire loads 


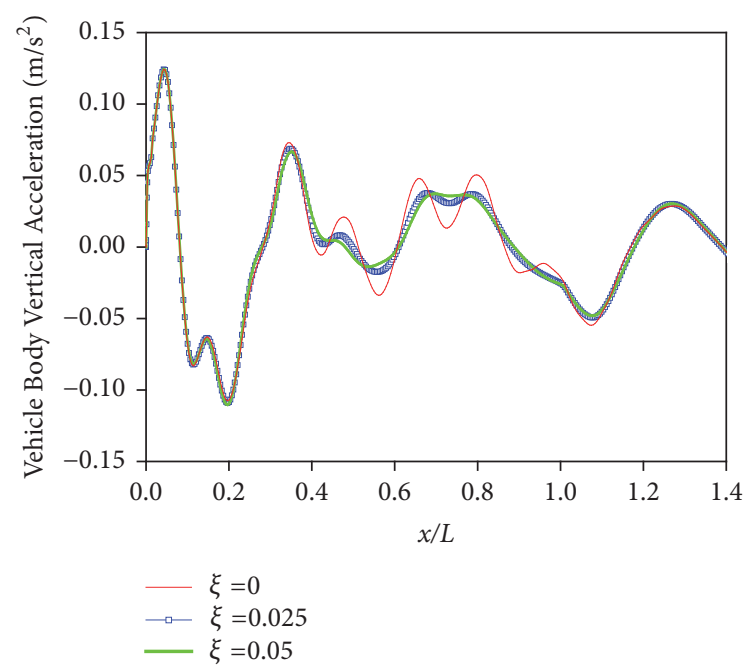

FIGURE 18: Vertical acceleration of vehicle body with different damping.

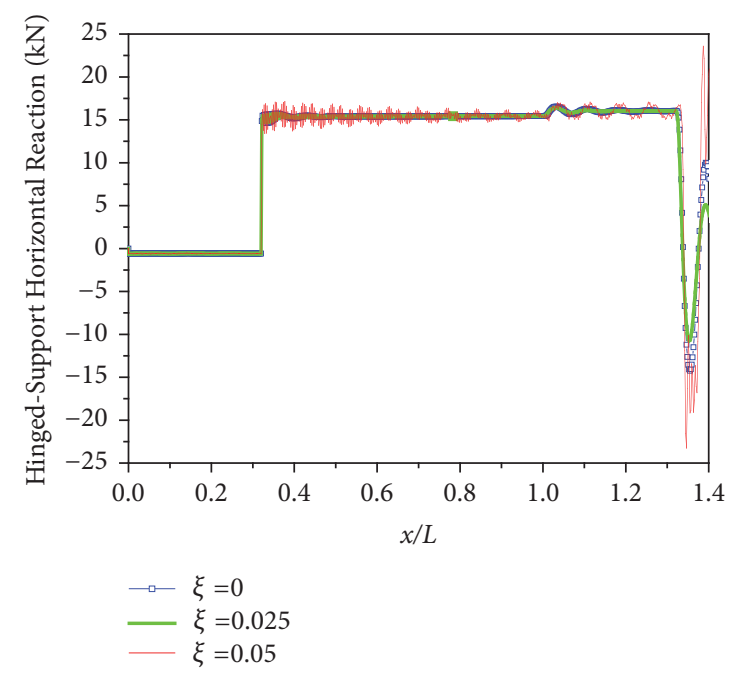

FIgURE 19: Longitudinal reaction at hinged support of simply supported beam with different damping.

for acceleration and braking. During the speeding up stage, larger acceleration leads to smaller vertical acceleration of the beam, while during braking stage, larger acceleration leads to larger vertical acceleration of the beam. With the increase of time, the vertical acceleration of the beam mainly depends on the moving speed of the vehicle. (2) Sudden increase of the vertical acceleration of the beam can be observed as the rear wheel enters on the beam and the front wheel leaves the deck. Sudden acceleration or braking causes a pitching motion of the vehicle body and leads to the larger vertical vehicle response in higher acceleration. (3) The longitudinal reaction force has obvious sudden change at the instant when the front wheel or rear wheel enters or leaves the beam. The change level is different for the acceleration and braking because of the different mechanisms of the longitudinal tires forces. (4) Road roughness and bridge damping have great effects on the vertical responses of the bridge and the vehicle but have limited effects on the longitudinal reaction force at the hinged support.

\section{Data Availability}

The data used to support the findings of this study are available from the corresponding author upon request.

\section{Conflicts of Interest}

The authors declare that there are no conflicts of interest regarding the publication of this paper.

\section{Acknowledgments}

The authors are grateful for the financial supports from the National Natural Science Foundation of China (51508480, 51525804), the Fundamental Research Funds for the Central Universities (2682016CX018), and the open project of the Transport Industry Key Laboratory for Wind Resistance Technique in Bridge Engineering (KLWRTBMC14-02).

\section{References}

[1] T. E. Blejwas, C. C. Feng, and R. S. Ayre, "Dynamic interaction of moving vehicles and structures," Journal of Sound and Vibration, vol. 67, no. 4, pp. 513-521, 1979.

[2] Y.-B. Yang and B.-H. Lin, "Vehicle-bridge interaction analysis by dynamic condensation method," Journal of Structural Engineering, vol. 121, no. 11, pp. 1636-1643, 1995.

[3] X. Li, W. Ma, and S. Qiang, "Coupling vibration analysis of vehicle-bridge system by iterative solution method," Journal of Vibrationand Shock, vol. 21, no. 3, pp. 21-25, 2002 (Chinese).

[4] N. Zhang and H. Xia, "Dynamic analysis of coupled vehiclebridge system based on inter-system iteration method," Computers \& Structures, vol. 115, pp. 26-34, 2013.

[5] Y.-B. Yang and Y.-S. Wu, "A versatile element for analyzing vehicle-bridge interaction response," Engineering Structures, vol. 23, no. 5, pp. 452-469, 2001.

[6] S. S. Law and X. Q. Zhu, "Bridge dynamic responses due to road surface roughness and braking of vehicle," Journal of Sound and Vibration, vol. 282, no. 3-5, pp. 805-830, 2005.

[7] H. Azimi, K. Galal, and O. A. Pekau, "A numerical element for vehicle-bridge interaction analysis of vehicles experiencing sudden deceleration," Engineering Structures, vol. 49, pp. 792805, 2013.

[8] L. Deng, F. Wang, and W. He, "Dynamic impact factors for simply-supported bridges due to vehicle braking," Advances in Structural Engineering, vol. 18, no. 6, pp. 791-801, 2015.

[9] E. J. OBrien, D. Cantero, B. Enright, and A. González, "Characteristic Dynamic Increment for extreme traffic loading events on short and medium span highway bridges," Engineering Structures, vol. 32, no. 12, pp. 3827-3835, 2010.

[10] W. Zhang and C. S. Cai, "Fatigue reliability assessment for existing bridges considering vehicle speed and road surface conditions," Journal of Bridge Engineering, vol. 17, no. 3, pp. 443453, 2012.

[11] Y. Li, N. Chen, K. Zhao, and H. Liao, "Seismic response analysis of road vehicle-bridge system for continuous rigid 
frame bridges with high piers," Earthquake Engineering and Engineering Vibration, vol. 11, no. 4, pp. 593-602, 2012.

[12] P. Antolín, N. Zhang, J. M. Goicolea, H. Xia, M. Á. Astiz, and J. Oliva, "Consideration of nonlinear wheel-rail contact forces for dynamic vehicle-bridge interaction in high-speed railways," Journal of Sound and Vibration, vol. 332, no. 5, pp. 1231-1251, 2013.

[13] M. M. Ettefagh, D. Behkamkia, S. Pedrammehr, and K. Asadi, "Reliability analysis of the bridge dynamic response in a stochastic vehicle-bridge interaction," KSCE Journal of Civil Engineering, vol. 19, no. 1, pp. 220-232, 2015.

[14] D. Crolla and F. YU, Vehicle dynamics and control, China communication press, Beijing, China, 2004.

[15] C. S. Cai and S. R. Chen, "Framework of vehicle-bridge-wind dynamic analysis," Journal of Wind Engineering \& Industrial Aerodynamics, vol. 92, no. 7-8, pp. 579-607, 2004.

[16] B. Wang, Y. Xu, and Y. Li, "Nonlinear safety analysis of a running road vehicle under a sudden crosswind," Journal of Transportation Engineering, vol. 142, no. 2, Article ID 04015043, 2016.

[17] K. Bogsjö, "Coherence of road roughness in left and right wheelpath," Vehicle System Dynamics, vol. 46, supplement 1, pp. 599609, 2008.

[18] M. Shinozuka, "Simulation of multivariate and multidimensional random processes," The Journal of the Acoustical Society of America, vol. 49, no. 1, pp. 357-368, 1971.

[19] ISO, Mechanical vibration-road surface profiles-reporting of measured data, 1995.

[20] Z. S. Yu, Automobile theory, China Machine Press, Beijing, China, 2009, in Chinese.

[21] S. M. Cui, Automotive System Dynamics, Beijing University Press, Beijing, 2014, in Chinese.

[22] B. Wang and Y.-L. Xu, "Safety analysis of a road vehicle passing by a bridge tower under crosswinds," Journal of Wind Engineering \& Industrial Aerodynamics, vol. 137, pp. 25-36, 2015. 


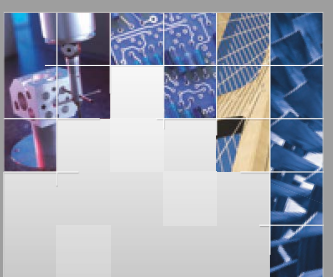

\section{Enfincering}
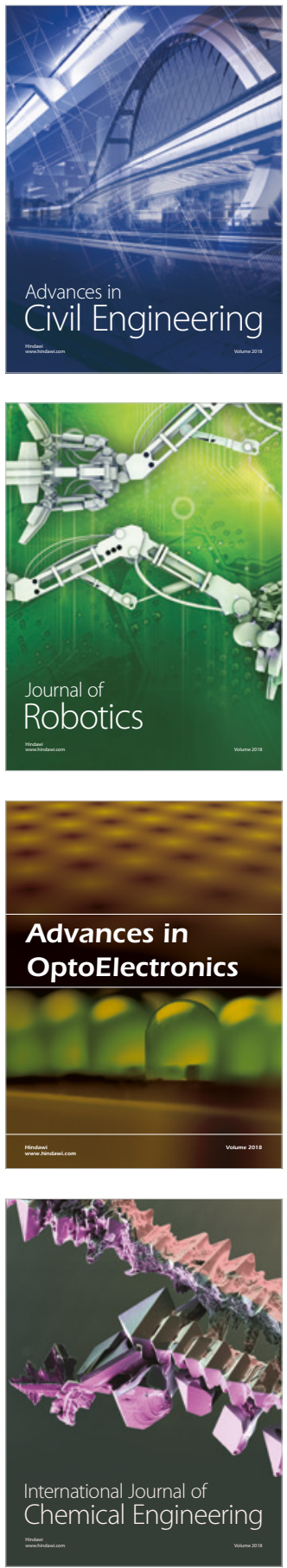

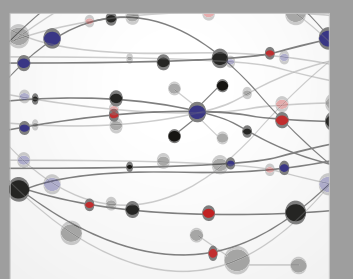

\section{Rotating \\ Machinery}

The Scientific World Journal

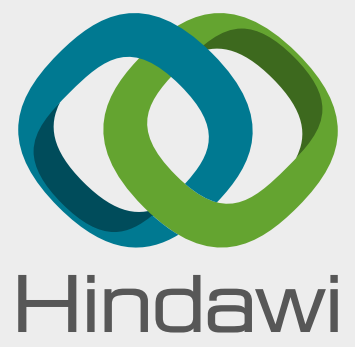

Submit your manuscripts at

www.hindawi.com
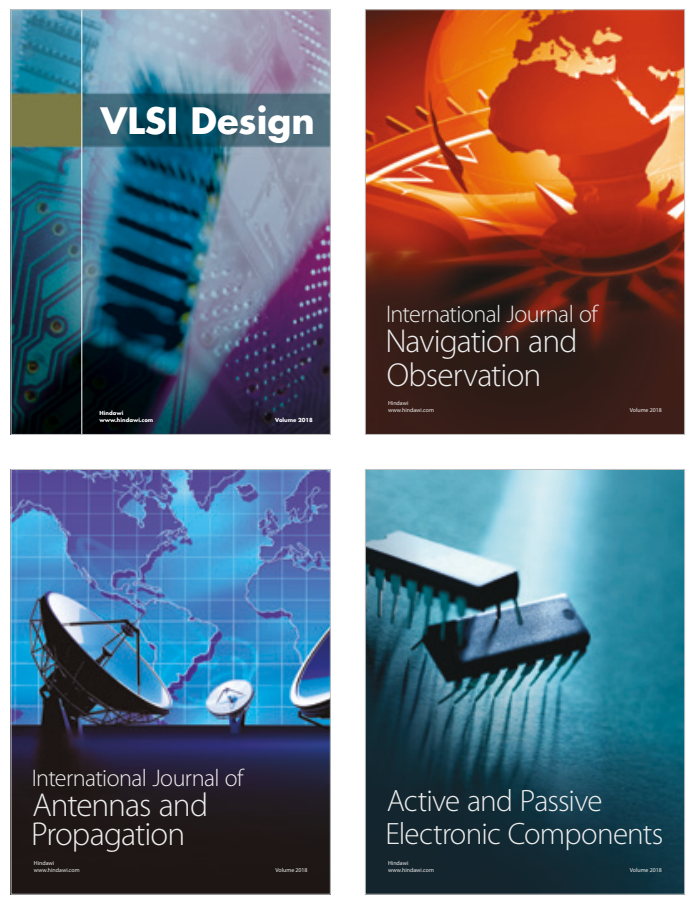
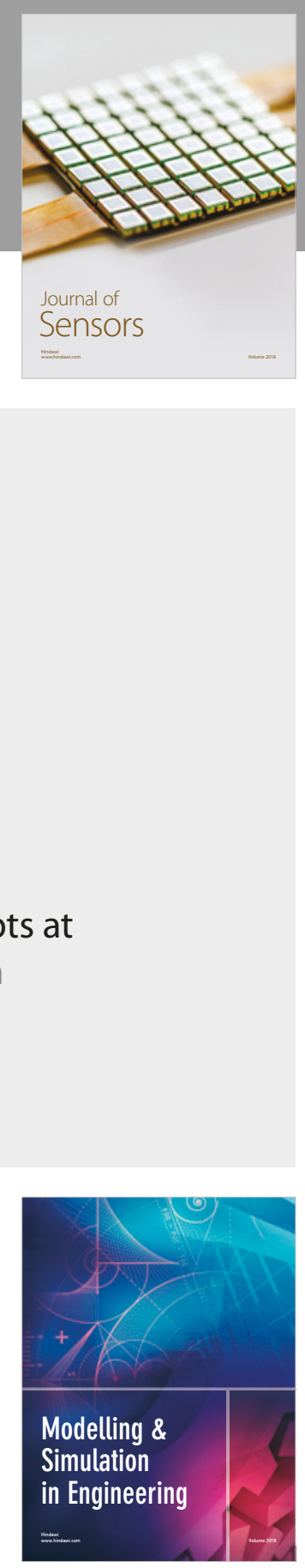

\section{Advances \\ Multimedia}
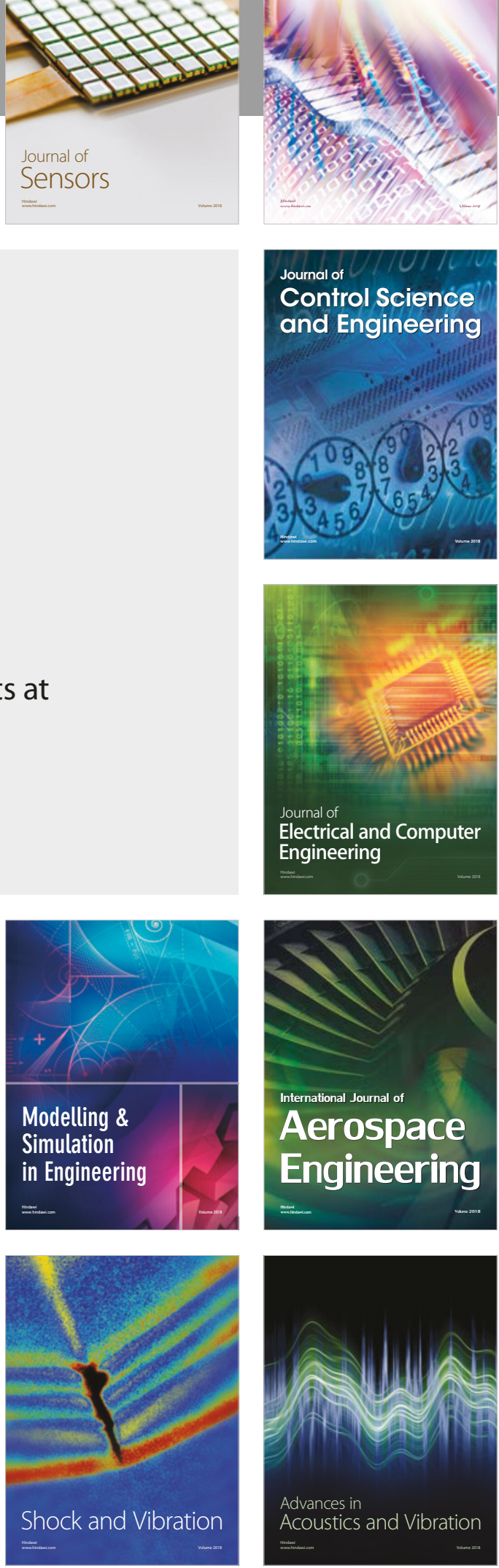